\title{
Lapurdum
}

Euskal ikerketen aldizkaria | Revue d'études basques |

Revista de estudios vascos | Basque studies review

19 | 2016

Numéro XIX

\section{Laguntzailea aditz sintetiko gisa ekialdeko hizkeretan}

\section{Ricardo Etxepare}

\section{OpenEdition}

\section{Journals}

Édition électronique

URL : https://journals.openedition.org/lapurdum/3350

DOI : 10.4000/lapurdum.3350

ISSN : 1965-0655

\section{Éditeur}

IKER

Édition imprimée

Date de publication : 1 janvier 2016

Pagination : $257-269$

ISBN : 978-2-95534-134-6

ISSN : $1273-3830$

Référence électronique

Ricardo Etxepare, «Laguntzailea aditz sintetiko gisa ekialdeko hizkeretan», Lapurdum [Linean], 19|

2016, Sarean emana----an 01 janvier 2021, kontsultatu 03 septembre 2021. URL: http://

journals.openedition.org/lapurdum/3350 ; DOI: https://doi.org/10.4000/lapurdum.3350 


\section{Laguntzailea aditz sintetiko gisa ekialdeko hizkeretan}

Ricardo ETXEPARE

CNRS-IKER UMR5478

\section{Sarrera}

Erdialdeko eta mendebaldeko euskalkiek ez bezala, ekialdekoek ${ }^{1} N Z$-hitz/Galdegai Laguntzaile hurrenkerak onesten dituzte. Lan honetan erakutsi nahi nuke hurrenkera hori berez aditz sintetikoekin posible dela egun euskararen aldaera guzietan, eta XVI eta XVIII. mende bitarteko mendebaldeko testu zaharretan ongi lekukotua dela laguntzaileentzat. Aditz sintetikoek, euskarazko beste aditz forma jokatuekin alderatzen baditugu, erro lexikodun aditz klase bakarra osatzen dute. Hipotesirik sinpleena ekialdeko laguntzaileari buruz, da aukeran hizkera horietako laguntzaile jokatuak erro lexiko baten jabe izan daitezkeela, eta hala denean aditz sintetikoen portaera morfosintaktikoa erakusten dutela. Ekialdeko hizkeren ezaugarri berezi hau kontestu diakronikoan ezarri behar da. Euskarazko aditz forma analitikoak aditz biko egituretatik heldu dira, Mounholek $(2006,2008,2011,2013)$ erakutsi bezala. Iduriz, ekialdeko hizkerek adizki ezaugarri hondar bati eutsi diote beren laguntzaileetan, aditz sintetiko gisa emateko aukera gordeaz.

\section{Laguntzaileak aditz perifrasietan}

Euskarazko aditzen forma jokatu produktibo bakarra analitikoa da, jakina denez.

1. Zuazok (1998) proposaturiko euskalki sailkapena nere egiten dut. Sailkapen horren arabera, euskarak baditu sei esparru dialektal nagusi : Bizkaiera edo mendebaldekoa, erdialdekoa edo Gipuzkera, Goi-Nafarrera, Ekialdeko Nafarrera, Nafar-Lapurtera eta Zuberera. Lan honetarako, mendebalde eta erdialdeko euskalkiak, Nafar-Lapurtera eta Zuberera hartuko ditut aintzat. Azken biak « ekialdeko euskalkiak » kategoria zabalago baten pean ezarriko ditugu, axola zaigun fenomenoarentzat berdin portatzen baitira. Hortik ekialdeko euskalkiei egiten zaien erreferentzia zehazgabea. Dialektologoek, omendua denak barne, barkatuko ahal didate. 
Aditz lexikoa aspektu atzizki batekin batzen da, eta denbora, modalitatea eta komunztadura aspektu sintagmatik aparte osatzen den laguntzaile bati lotuak agertzen dira :
a. Nik zuri liburuak eraman dizkizut
b. Nik zuri liburuak eramaten dizkizut

(Perifrasi burutua)

(Perifrasi burutugabea)

Laguntzaileak, alde honetatik, izaera funtzional hutseko elementu gisa ikus daitezke, perifrasiaren aditz lexiko bakarraren eta komunztadura erregela orokorren araberako forma hartzen dutenak. Haddicanentzat (2005), perifrasiak izaera funtzionaleko birregituraketa konfigurazioak dira (ikus 4.1. atala), Cinque-ren (2006) lanaren izpirituan. Arregi eta Nevinsentzat (2013), Morfologia Banatuaren esparruan ari direnak, Denbora eta Konplementatzaile buruen lexikalizazioari dagozkie. Laguntzaileen izaerari buruzko lan orokorretan ez da ohikoa izaten hizkeren arteko diferentziak aipatuak izan daitezen, eta horrela da aurreko lan horietan ere. Alta bada, ekialdeko hizkerek berezitasun batzu erakusten dituzte laguntzailearen distribuzioaren aldetik. Nabarmena den bat aipatzearren, ekialdeko hizkeretan laguntzaileak galdegaiaren edo NZ-hitzaren ondo-ondotik ager daitezke (Lafitte, 1944: 47), gainerako euskalkietan ez bezala:
a. Nor da hil?
b. Piarres da hil

Hitz hurrenkera hauek orokorrak diren (3) koekin bizi dira hizkera horietan beretan:
a. Nor hil da?
b. Piarres hil da

(2) eta (3) ko egiturek ez dute baitezpada interpretazio bera, Duguine eta Irurtzunek (2010) arrazoi badute. Haien arabera, (2) ko perpausetako galdegaia, (3) koa ez bezala, kontrastiboa da. Interpretazio diferentzia gora behera, galdegin genezake zergatik diren (2) ko hitz hurrenkerak posible ekialdeko hizkeretan eta ez erdialde edo mendebaldekoetan. Galdera hori bera mendebaldeko lehenagoko aldaeretara heda daiteke, ohartzen garelarik ekialdeko hitz hurrenkerak orduan ere posible zirela euskalki eremu hartan, XVI eta XVIII. mende arteko ondoko etsenpluek erakusten duten bezala: ${ }^{2}$

2. Iduri luke Lazarragaren kasuan inbertsioak ugariago izatearekin batera halako funtzio narratibo zabalago baten baitan kokatu behar direla. Horren erakusgarri garbia da aditz laguntzailea topikoen ondotik agertzea:Silveriok len esan dogun berbaok entzun egianean, zidin andiro enojadu (Artzain nobela).

Azterkizun gelditzen da, jakina, inbertsioaren sintaxi orokorrak Lazarragan hartzen duen itxura. 
(4) a. Doguna jan dogu eta arlot gara biortu (RS 329)

b. ...euren injuria dabe bengatu

(Butroeko Andrearen Eresia, Arriolabengoa: 86)

c. ... nola doçu orrein gaxqui/ceure matraz doraduoc gobernaetan?

(Lazarraga, Artzain liburua, 1151-1152)

d. Zerureanik dakart enbajadea/ zeu zarala izango jaunaren amea (Barrutia, Acto: 41-42)

Lan honetan (2) eta (4) bezalako hurrenkeren azpian laguntzailearen aditz izaerari loturiko baldintza morfosintaktikoak daudela defendatuko dut. Baldintza horiek euskarazko perifrasien historiaren baitan esplikatu behar direla erakusten saiatuko naiz, Mounole-n lanari segituaz.

\section{Laguntzailea aditz bakar gisa}

Ekialdeko hizkerak laguntzaileaz baliatzen dira erdialdeko eta mendebaldeko euskalkiek aditz sintetikoak erabiltzeko joera duten ingurune sintaktiko beretan. Sinplifikatuaz, honelako paraleloak eraiki ditzakegu ekialde/erdi-mendebaldeko hizkera multzoen artean:

(5) a. Etxean naiz (Ekialdea)

b. Etxean nago (Erdialde/Mendebaldea)

(6) a. Badut oto bat (Ekialdea)

b. Kotxe bat daukat (Erdialde/Mendebaldea)

(5)-(6) ko aurkaritzak (laguntzaileak aditz nagusi gisa erabiltzeko posibilitateari dagozkionak) honela deskriba daitezke: erdialdeko eta mendebaldeko hizkerek aditz sintetikoak erabiltzera behartuak diren zenbait kontestu sintaktikotan, ekialdeko hizkerek laguntzaileen klaseari dagokion adizki jokatua erabil dezakete. Erabilera hau hautazkoa da hizkera horietan, egon ere balia daitekeelarik leku-predikatuetan bederen:

(7) Lehen minixtroa Kanadan dago lau egunentzat (Herria aldizkaritik)

Aurreko fenomenoarekin bezala, portaera beraren aztarnak aurki daitezke bizkaiera zaharrean, Lasturko Miliaren eresia lekuko (Mitxelena, TAV:76) izan-entzat, eta Arrasateko erreketari buruzko bertsoak edun-entzat (Mitxelena, TAV: 82):

(8) a. Ate arte zabalean oy çan (Milia Lasturko)

b. Zaldibarrek bere partea debala (Arrasateko erreketa)

Aditz sintetikoak eta laguntzaileak alderatuz gero, bien arteko diferentzia honetara ekar daiteke: aditz sintetikoak erro lexiko baten jabe dira; laguntzaileak printzipioz ez. Esanguratsua izan daiteke, hartara, ekialde muturreko hizkeretan (Orotarikoaren arabera historikoki Amikuze eta Zuberoan) laguntzaile iragankorrarentzat aditz forma ez jokatu berezitu bat aurkitzea, $u k(h)$ an edo $u k(h) e n$. Laguntzaile iragankor eta iragangaitzentzat forma 
ez jokatu berezituak izatea bizkaiera zaharrean lekukotua den zerbait da baitaere, nahiz kasu horretan forma ez jokatua edun-ena izan, ez ukan-ena:

(9) Atseyn andia da amore eutea (Oihenarten Art Poétique-eko kantu bizkaitarra, Sarasola, Contribucion: 220)

Ekialdeko eta erdialde-mendebaldeko hizkeren arteko diferentzia bi modutan uler daiteke: (i) ekialdeko laguntzaileen berezitasun baten gisa (ekialdean, ongi konprenitzen ez ditugun arrazoinengatik, laguntzaileek distribuzio libreagoa dute), edo (ii) aditz sintetikoen klasearen hedapen gisa (ekialdeko laguntzaileak aditz sintetikoak izan daitezke). Bigarren aukera ezagun dugunaren esparruan kokatzen denez, hobestekoa dela iruditzen zait. Lakaren (1990) analisi klasikoaren arabera, aditz sintetikoen berezitasuna aditz erroa denborarekin zuzenean lotzen dela da:

(10) $\quad\left[_{\text {DenbP/KomP }}\right.$ erroa+D/Kom $\left[_{\mathrm{VP}}(\right.$ erroa $\left.\left.) \ldots\right]\right]$

Aditz sintetikoak (10) bezalako egitura baldin badute, ekialdeko laguntzaileek ondoko forma dute edo izan dezakete:

(11) $\left[_{\text {DenbP/KomP }}\right.$ erroa+D/Agr $\left[{ }_{V}(\right.$ erroa $\left.\left.)[\mathrm{v}[\mathrm{VP}]]\right]\right]$

Momentuz zehaztugabe utziaz jatorrizko lotgunea (hemen $v$ gisa irudikatu dudana), zer beste ebidentzia ekar daiteke ekialdeko laguntzaile jokatuak aditz sintetikoen sailean eman daitezkeela defendatzeko?

\section{Adizki jokatuen distribuzio hertsidurak}

\subsection{Adizki jokatuak perpausaren buruan}

Adizki jokatuek, laguntzaileak izan edo aditz sintetikoak, hertsidura zorrotzak dituzte kokapenaren aldetik: ezin dira perpausaren lehen posizioan agertu. Hau da, (12) bezalako aditz jokatu bat ezinezkoa da bere horretan, argumentuak isiltzea zilegi bada ere euskaraz.

$$
\text { *__ daki }
$$

(12) bezalako perpaus batek euskarri morfosintaxiko bat behar du euskararen gramatikaren arabera gauzatua izateko. ba- aurrizki betegarria eransten badiogu perpausa onargarria bilakatzen da:

\section{(13) Ba-daki}

Beste elementu batzuk, hala nola ezeztapenak edo galdegaiak adizki jokatua lehen posiziotik geriza dezakete: 
(14) a. Ez daki
b. JONEK daki

Adizki jokatuaren aitzinetik agertzen diren osagai guziak ez dira halabeharrez haren mesedetan gertatzen. Zenbait elementuk, topikoek kasu, ez dute forma jokatua aipatu posiziotik salbatzen (Ortiz de Urbina, 1995):

$$
\text { *Jonek, daki }
$$

Gauza ezaguna da topikoek beren sintagma intonazional propioa ekartzen dutela (ikus e.g. Nespor eta Vogel 1986). Lehen posizioa beraz intonazio sintagma baten barnean ulertu behar da. Posizio hertsidura hau ulertzeko modu bat ondokoa izan daiteke: adizki jokatuak morfofonologikoki beregainak ez diren elementuak dira (Ortiz de Urbina, 1994; Elordieta, 1997; Etxepare eta Uribe-Etxebarria, 2009), eta horrenbestez ez dira gauza sintagma intonazional baten ezkerreko ertza zedarritzeko. Horretarako nahitaez azentudun beste elementu bati lotu behar zaizkio beren intonazio sintagman. Ortiz de Urbinaren proposamen bat moldatuaz, hertsidura hori honela formula genezake (D hizkiak denbora, eta 1 zenbakiak posizioa markatzen dutelarik):

(16) *Dl Euskaraz (intonazio sintagma baten barnean)

\subsection{Aditz sintetikoak versus laguntzaileak}

Erdialdeko eta mendebaldeko hizkeretan aditz sintetikoak eta laguntzaileak konparatuz gero berehala ohartuko gara batzuen eta besteen kokapen galdakizunak ez direla arras berdinak: laguntzaileek ezeztapena eta aditz multzoa balia dezakete lehen posizioa saihesteko; aditz sintetikoek berriz polaritatea, aditz multzoa eta galdegaia baliatzen ahal dute:
a. Etorri da
(Erdialde-mendebaldea)
b. Ez da etorri
c. ${ }^{*} \mathrm{JON}$ da etorri
a. JON dator
(Erdialde-mendebaldea)
b. Ez/ba-dator

Kontua da ekialdeko hizkeretan (17c) bezalako hurrenkerak posible direla, hain zuzen ere lan honen abiaburuan diren galdegai indartuzko formetan edo NZ-galderetan ((2a,b) behean errepikatuak):
a. Nor da hil?
b. Piarres da hil

Gurutzatzen baditugu laguntzaileek eta adizki sintetikoek lehen posizioa saihestea ahalbidetzen duten konfigurazio sintaktikoak eta hizkera esparruak, ondoko taulak ateratzen zaizkigu : 
(19) Laguntzaileak lehen posizioa saihestea ahalbidetzen duten egiturak

\begin{tabular}{|c|c|c|}
\hline LAG & Ekialdea & Besteak \\
\hline NZ/Galdegaia & BAI & EZ \\
\hline Aditz Multzoa & BAI & BAI \\
\hline Polaritatea & BAI & BAI \\
\hline
\end{tabular}

(20) Aditz sintetikoak lehen posizioa saihestea ahalbidetzen duten egiturak ${ }^{3}$

\begin{tabular}{|c|c|}
\hline ADITZ S. & EUSKALKI GUZIAK \\
\hline NZ/Galdegaia & BAI \\
\hline Aditz Multzoa & ---- \\
\hline Polaritatea & BAI \\
\hline
\end{tabular}

Taulak gertutik begiratzen baditugu, nabarmena da ekialdeko laguntzaileen eta aditz sintetikoen portaera paraleloa. Zer ondorio atera behar dugu honetatik? Aipaturiko paralelotasun horietatik abiatuta, bi hipotesi baizik ez dira posible: edo ekialdean aditz lexikoari laguntzen dioten adizki jokatuak aditz sintetikoak dira; edo adizki laguntzaile jokatuak aditz sintetiko zein laguntzaile gisa erabiliak izateko aukera dute, noiz nola. Bi hipotesi horiek honela formula daitezke:

Lehen hipotesia:
a. ... [ du T/Agr [ v [ VP]]]
(Euskalki guziak, ekialdekoak barne)
b.... [ T/Agr $\left[{ }_{\mathrm{V}}\right.$ erroa $\left.\left.[\mathrm{v}[\mathrm{VP}]]\right]\right]$
(Ekialdekoak bakarrik)

Bigarren hipotesia

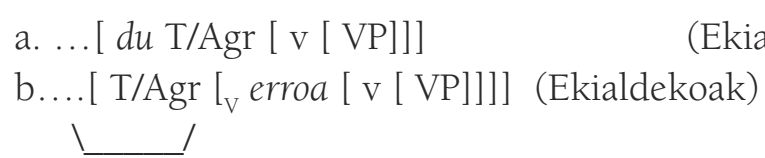

Lehen begiratuan, emango luke lehen hipotesia dela aukera handienak dituena: laguntzaileak aditz sintetikoak izango balira nahitaez ekialdeko euskalkietan, aditz multzoaditz sintetiko segidak posible izan beharko lirateke, bizkai mendebaldeko zenbait lekutan

3. Aditz Sintagmari dagokion hutsartea bete gabe uzten dut. Aditz sintetikoetan aditz erroa zuzenean batzen zaio denbora buruari, eta aditz multzoa ez da beraz osagai gisa mugitzen. 
posible diren bezala: ${ }^{4}$

(23) Etorri dator (Mendebaldeko zenbait aldaera)

Baina halakorik ez da ekialdeko euskalkietan. Lehen hipotesiaren aldeko ebidentzia zuzenagoa biltzeko moduan gaude, hala ere, ondoko atalean ikusiko dugun bezala.

\section{Galdegai-adizki jokatu hurrenkerak eta birregituraketa}

Lehen hipotesiaren aldeko ebidentzia garbia birregituraketa konfigurazioen eta aipatu hurrenkeren arteko erlazioan aurki daiteke. Erakutsiko dut ekialdeko hizkeretan adizki jokatua laguntzaile huts gisa portatzen denean Galdegai-Adizki jokatu hurrenkerak ezinezkoak direla. Honek erakusten du batetik hurrenkera horiek aditz sintetikoekin lotuak direla nahitaez, eta beraz ekialdeko laguntzaileak adizki sintetiko gisa aritzeko ahalmena dutela, eta bestetik ekialdeko hizkera horietan beretan, aditz lexikoa laguntzen duen adizki jokatuak izaera anbiguoa duela: erro lexikodun elementu bat izan daiteke, edo Komunztadura eta Denbora buruen lexikalizatzaile hutsa (hots, funtzio-buru bat).

\subsection{Progresiboa eta birregituraketa}

Nafar-lapurterak birregituraketa adibide garbi bat eskeintzen du progresibozko egituren esparruan. Euskalki guziek partekatzen dituzten egitura progresiboak bi perpausetakoak dira. Batetik bi izen sintagma absolutibo agertzen dituzte, eta aspektu markak har ditzakeen aditz bat dute (ari) buru. Ari-k inesibozko perpaus nominalizatu bat hartzen du osagarritzat:

(24) Xabier [ _ liburuak erosten] ari da

Ari progresibozko aditzak aspektu burutuari eta burutugabeari dagozkien markak har ditzake:

(25) a. Xabier [ _ liburuak erosten] ari-tzen da

b. Xabier [_ liburuak erosten] ari-tu da

Ari aditzak forma jokatugabeak ere baditu (26a,b), eta aditz oin gisa ager daiteke subjunktiboan (27):

(26) a. Ez dakit horretan aritu ala ez

b. Horretan aritzea alferrikakoa da

4. Hurrenkera hauek galdegai estrategiaren aldaerak ematen dute, zeinetan aditz izena fokalizatua den (ikus Elordieta eta Haddican, 2014, analisi xehe batentzat). Ez dirudi funtsean axolazkoak direnik aztertzen ari garen konfigurazioentzat. 
(25a,b) ko egiturak bi perpausetako kontrol egitura gisa analizatuak izan dira (Hualde and Ortiz de Urbina, 1987; Laka, 2006). Analisi hori ontzat jotzen dut goiko egiturentzat.

Bizkitartean, ekialdeko hizkerek konfigurazio alternatibo bat garatu dute XIX. mendetik aurrera progresibozko egituretan. Konfigurazio alternatibo horretan: (i) laguntzailea menpeko aditz lexikoaren araberako forma du; (ii) azpiko aditzari dagokion kasu lerrokatzea erakusten du; (iii) laguntzaileak menpeko perpauseko objektuarekin komunztadura egiten du numero eta pertsonan; eta (iv) kontestu horretan, ari aditzak ez dezake aspektu atzizkirik har. Konparatu (28a,b) (Lafitte, 1944).

(28) a. Xabier ura karriatzen ari da

b. Xabierrek ura karriatzen ari du

(28a) perpausak ez bezala, (28b)-k laguntzaile iragankorra erakusten du, karriatu aditzari dagokion gisa, eta haren subjektuak ergatibo kasua du, eta ez absolutiboa, (28a)-n bezala. Konfigurazio hau ezinezkoa da aspektu atzizkiekin batera:

(29) a. *Xabierrek ura karriatzen aritzen du

b. *Xabierrek ura karriatzen aritu du

(29) ko perpausen gramatikaltasun eza nola ulertu behar dugu? (29)-k aspektu atzizki bakarra har dezake. Murriztapen hori interpretatzeko modu natural bat da egitea (29)-k aditz bakarra duela, eta beraz, ari progresiboak ez duela aditz izaerarik kasu honetan. Kontrol kasuetan bi perpausetako egitura bat dugun bitartean, (29) perpaus bakarreko egitura da. Honelako egitura alternantziak birregituraketa fenomeno orokorraren erakusgarri dira (Rizzi, 1982).

Birregituraketaren ikuspegi aski hedatu baten arabera, zenbait aditzek, daukaten esanahiagatik buru funtzionalen ekarpen semantikoarekin bat egiten dutelako, zuzenean buru funtzional bat lexikaliza dezakete. Ikuspegi honen arabera (Cinque, 2006), itxuraz lexikoa den aditz batek egiazki tasun funtzional bat kodetzen du. Ikuspegi hori honela irudika dezakegu:

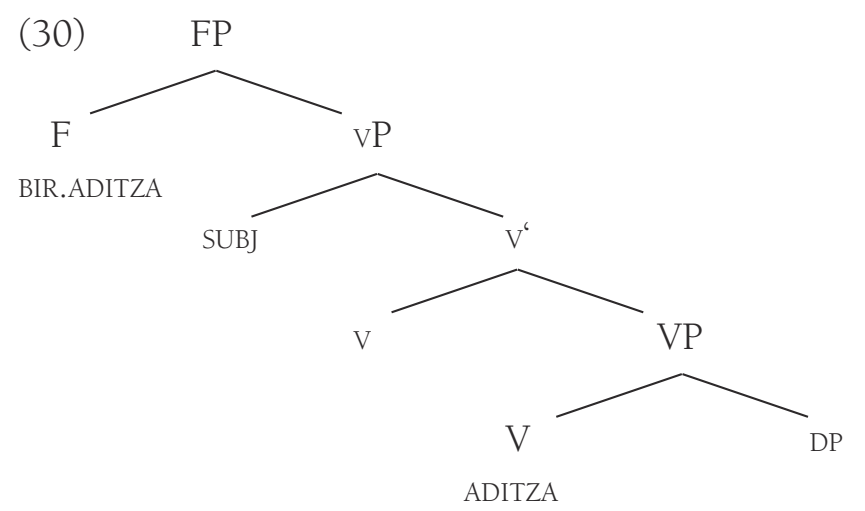

Horrek esan nahiko luke (26b) bezalako perpaus batean, ari progresibozko marka ez dela aditz gisa lotzen sintaktikoki, baizik eta funtzio buru baten gisa proiektatzen dela perpaus 
egituran. Hipotesi honek ongi azaltzen ditu gainerako ezaugarriak ere: perpausak erakusten duen kasu distribuzioa aditz lexikoari dagokiona da, eta laguntzailea bera ere aditz lexikoaren araberakoa da.

Perpausaren aspektu eremua hedatu egiten badugu, progresibozko bi egiturak ondoko konfigurazioen bitartez irudika ditzakegu. (28a)-n, ari aditz gisa lotua zaio egiturari, gainetik partizipiozko eta gerundiozko tasun morfosintaktikoak dituelarik (Cinque, 2004:133):

$$
\ldots \mathrm{F}_{\text {Ohikoa }} \ldots \mathrm{F}_{\text {Gerundioa }} \ldots \mathrm{F}_{\text {Konpletiboa }} \ldots\left[_{\mathrm{VP}} \text { ari }\left[_{\text {Postposizio S }} \ldots \mathrm{VP} \ldots\right]\right]
$$

(28b)-n, ari zuzenean gerundiozko buruan sortua da, eta buru funtzional baten gisa portatzen da.

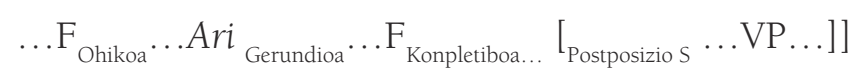

\subsection{Birregituraketa eta perpausaren ezker muturreko hitz hurrenkera}

Ari buru funtzional bat bada (28b)-n, Aditz Sintagmatik kanpo dagoena, eta adizki jokatua oraindik gorago badago perpaus egituran, ondorioztatu beharrean gara laguntzailea buru funtzional batean sortua dela ere bai. ${ }^{5}$ Arregi eta Nevins-en proposamenari helduaz, egin dezagun laguntzailea kasu horretan denbora eta komunztaduraren euskarri huts bat dela. Honek predikzio bat egiten du: begiratzen baldin badugu zein eratako elementuek gerizatzen duten adizki jokatua lehen posiziotik kasu horietan, laguntzaileari dagozkionak izan behar dute, ez aditz sintetikoei dagozkienak. Predikzio hori betetzen da, (31-32) kontrasteek aditzera ematen dutenez: (32b)-k ez du NZ-hitza onartzen adizki jokatuaren aitzinean, mendebaldeko laguntzaileek onartzen ez duten bezala.

(31) a. Nor ari da ura karreatzen?

b. Nor da ura karreatzen ari?

(32) a. Nork ari du ura karreatzen?

b. *Nork du ura karreatzen ari?

Arrazoibide honen arabera, ekialdeko laguntzaileak erro lexiko baten jabe izan daitezke edo denbora eta komunztadurarentzako euskarri hutsa.

5. Aurreko arrazoibideak baditu argitu gabeko alderdi batzuk. Batetik, arrazoibidea zuzena izateko, egin behar dugu aditz izaera duen ari formak ez dezakeela bere baitan gerundiozko edo aspektu esparruaren goiko egitura funtzionalik bere osagarriaren parte gisa har. Ari-ren osagarria, honen arabera, sintaktikoki mugatua da, kontrol egitura batenganik espero zitekeen bezala, baina ez baitezpada kontrol predikatuen osagarrien inguruko teoria guziek onartuko luketen heinekoa. 


\subsection{Aditz sintetikoaren kategoriaz}

Aditz sintetikoek euskaraz ez dute aditz kategoria arrunt bat osatzen. Gaurko aditz sintetikoen klasea euskaraz klase itxia da, definitzen dituen ezaugarria (erro lexiko bat edukitzea) printzipioz lexikoi irekiari dagokion zerbait bada ere. Esistitzen diren aditz sintetiko gehienek badituzte komunzki buru funtzionalei egozten dizkiegun zereginak, hala nola aspektuaren adierazpenari dagozkionak edo modalitateari lotutakoak; eta paradigmatikoki ez dira osoak, neurri bateko edo besteko murrizketa erakusten dutelarik pertsona edo denbora marketan. Berrok (2015) Cinque-ren funtzio-buruen hierarkiarekin lotzen ditu, buru funtzionaletan loturiko erro lexikoak direla argudiatuz. Laguntzaileak gauzatuko lituzketen funtzio-buruak aditz sintagmaren inguruko funtzio buru aspektualak izango lirateke. Alde horretatik, aditz sintetikoek kategoria semilexikoen antza dute. Kategoria semi-lexikoen esistentzia, erabat gardenak diren buru funtzionalen eta izaera lexiko osoa duten kategoria lexikoen artekoa, taxonomikoki ongi bermatua dago birregitura fenomenoen alorrean. Aipatzekoak dira esate baterako Italierazko aspektu eta mugimendu aditzen inguruan egindako lan xeheak (ikus, Cardenaletti eta Giusti, 2001; Cardenaletti eta Shlonsky, 2004; eta nozioaren gainbegiratu orokor batentzat, Corver eta Van Riemsdijk, 2001). Cardinaletti eta Giustik (2001:1) honela definitzen dute aditz semilexikoen klasea mugimendu aditzez ari direlarik:

(33) Mugimendu aditz semi-lexikoak kategoria lexikoak dira buru funtzional gisa lotzen direnak perpausean

Aditz sintetikoen kasuan, aspektu mailako kategoria lexiko horiek denborari lotzen zaizkio buruz buruko mugimendu sintaktikoaren bitartez, ez baitago tartean traba egingo duen aspektu bururik, Lakak (1990) eta Berrok (2015) erakusten duten bezala.

\subsection{Identifikaziozko eta jabetzazko izan eta edun}

Hemen defendatzen dudan hipotesiarentzako zeharbidezko ebidentzia ematen dute euskaran orokorrak diren bestelako adizki jokatu batzuek. Euskalki guzietan, galdera hitzek eta galdegaiek adizki jokatua lehen posiziotik geriza dezakete identifikaziozko edo jabetzazko kontestuetan:

(34) a. Nor da hori?

b. Nork du horrelako zerbait?

Jabetzazko edun aditz lexiko gisa ematen da ingelesez (pace Kayne, 1993). Eta identifikaziozko izan aditzak forma lexiko desberdinak ditu zenbait hizkuntzatan identifikaziozko eta predikaziozko zereginentzat, esate baterako hizkuntza zeltikoetan. Hizkuntza horietan (eta ingelesarentzat ere) proposatu izan da identifikaziozko izan aditza aditz lexiko gisa portatzen dela (ikus Zaring, 1995).

\section{Ekialdeko hurrenkerak diakronian kokatuaz}

Lafon (1943), Mitxelena (1981), Haase (1994), Gomez eta Sainz (1995), eta bereziki Mounole $(2006,2008,2011)$, bat datoz euskarazko perifrasiak bi perpausetako egituretatik 
eratorriak direla esateko. Perfektuzko perifrasietara mugatuaz, Ledgeway-k (2012) egitura horien bilakaeraren inguruko iritzi zabalduena laburbiltzen du jatorrian perfektuzko forma erresultatibo bat dagoela dioenean. Latinezko (35) perpausak erakusten du forma hori:

(35) In ea provincia pecunias magnas collocatas habent

"Probintzia horietan ondasun handiak jarriaraziak dituzte"

(Zizeron)

(35) perpausean, habere aditza bi argumentu dituen aditz bat da, pecunias magnas osagarri duena. Partizipioa bigarren mailako predikatu bat da, eta bere subjektua ez da baitezpada habere aditzarena bera. Beste norbait izan daiteke delako probintzietan ondasunak paratu dituena. Perfektu erresultatiboa perfektu arrunta bilakatzen da partizipiozko sintagmaren subjektua habere-ren subjektu bera gisa obligatuzki interpretatzen hasten denean. Mounole-k azaldu bezala, antzeko prozesua ikus daiteke euskarazko perfektuzko perifrasietan ere. Horra esate baterako ekialdeko hizkeretatik ateratako bi etsenplu:

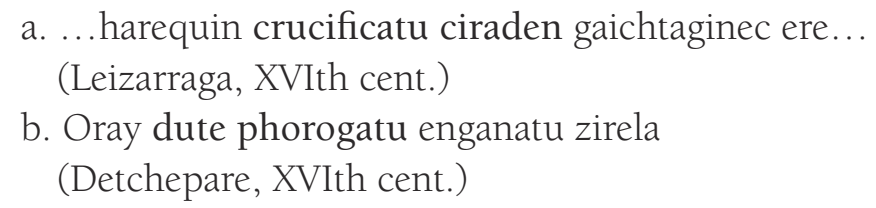

(36a,b)-n adizki jokatuak argumentu bakarreko edo biko aditzak dira, partizipioa bigarren mailako predikatu bat delarik, subjektu obiatibo batentzat lekua duena: (36a)n kriminalek ez dituzte beren buruak gurutziltzatu, gurutziltzatuak izan dira, eta (36b)-n froga-emailea (euskarazko lehen liburuaren idazlea) eta frogaren hartzaileak ez dira bistan denez jende berbera. Garai berean, mendebaldeko hizkerek egon eta edun dituzte horrelako egiturentzat. Perfektu erresultatiboarekin batera, garai hartako ekialdeko testuek badituzte ere perfektu arruntak. Egitura hau euskalki guzietakoa da gaur egun ere (Mounole, 2011: 47):

(37) a. Eztuçue iracurri David-ec gossez eguin çuena

(Leizarraga, XVI. mendea)

b. ... ayta-amaoc efini dave/ Flora oy encerraduric

(Lazarraga, XVI. mendea)

Mounole-n analisiari jarraiki, euskarazko perifrasiak bi perpausetako egituretatik eratorriak dira. Jatorrizko egituretan, adizki jokatua egiazko adizki bat da, izaera lexikoa duena. Egitura honek ondotik anbiguoa den bati ematen dio bidea: hartan, perifrasia egitura aldetik bitara uler daiteke, edo bi perpausetako egitura gisa (bi subjektuak desberdinak izan daitezkeelarik), edo subjektuak berdinak direnean, egitura gisa monoklausal gisa. Azken kasu honetan egitura anbiguoa izan daiteke kontrol egitura baten eta igoera egitura baten artean. Oinarrizko anbiguitate honek abiarazi bide zuen aditzak laguntzaile izatera bultzatu zituen gramatikalizazio prozesua (ikus Vincent, 1982, analisi zehatzago batentzat).

XVIII. menderako (36) bezalako egiturak desagertuak dira, erresultatibozko bi egituraren mesedetan. Batek, ekialdekoak, izan/edun aditz formak gordetzen ditu. Besteak, erdialde eta medebaldekoak, egon/edun formak baliatzen ditu (ikus Haase, 1992; Krajewska, 2013): 

a. Etxea saldua/saldurik da
(Ekialdea)
b. Etxea salduta dago
(Erdialdea eta mendebaldea)

Mounole-k erakusten duenez, ekialdeko hizkerek bilakaera mantsoagoa agertzen dute adizki forma jokatuen gramatikalizazioan. XVI. mendean oraindik lekukotuak daude bi perpausetako egitura garbiak, Leizarraga eta Etxepareren goiko adibideetan bezala. Ekialdeko laguntzaileek erro lexiko baten arrastoa gordetzea, aukeran aditz sintetikoen klasearekin bat eginez, bilakaera berant honen beste testigantza bat izan daiteke. Bestalde, laguntzaileen portaera berezi hori perifrasien historiarekin lotzekoa bada, ez da harritzekoa bestelako euskalkietan ere aurkitzea, perifrasien gramatikalizazioak laguntzaileen aditz izaera erabat lausotu baino lehenagoko garaietan. Egoera horri dagozkio, seguruenik, mendebaldeko testuetatik erauzitako NZ/Galdegai-Laguntzaile hurrenkerako aleak.

\section{Erreferentziak}

Arriolabengoa, Julen. 2008. Euskara Ibarguen-Cachopin kronikan. Testu zaharren ediziorako kontribuzioa. Bilbao: BBK Fundazioa eta Euskaltzaindia.

Arregi, Karlos and Andrew Nevins. 2013. Morphotactics. Basque Auxiliaries and the Structure of Spell Out. Berlin: Springer.

Berro, Ane. 2015. Breaking verbs: from event structure to syntactic categories in Basque. Doktorego tesia, Euskal Herriko Unibertsitatea (UPV-EHU)/Université de BordeauxMontaigne (UBM).

Bilbao, Gidor, Ricardo Gómez, Joseba A. Lakarra, Celine Mounole \& Blanca Urgell (arg). 2010. Lazarraga eskuizkribua: Edizioa eta azterketa. Vitoria-Gasteiz: Euskal Herriko Unibertsitatea.

Cardinaletti, Anna \& Ur Shlonsky. 2004. Clitic positions and Restructuring in Italian. Linguistic Inquiry 35 (4). 519-557.

Cinque, Guglielmo. 2006. Restructuring and Functional Heads. The Cartography of Syntactic Structures. Oxford: Oxford University Press.

Elordieta, Gorka. 1997. Morphosyntactic feature chains and phonological domains. Doctoral dissertation USC.

Duguine, Maia \& Aritz Irurtzun. 2010. Opérateurs d'exclusivité dans les questions et réponses en basque. Révue de Sémantique et Pragmatique 27. 105-117.

Etxepare, Ricardo \& Myriam Uribe-Etxebarria. 2009. Hitz hurrenkera eta birregituraketa Euskaraz. In Ricardo Etxepare, Ricardo Gómez \& Joseba A. Lakarra (arg) Festschrift for Beñat Oyharçabal, Anuario del Seminario de Filología Vasca «Julio de Urquijo» 43. 335-356.

Kayne, Richard. 1994. The Antisymmetry of Syntax. MIT Press.

Knörr, Endrike, Joseba A. Lakarra, Jon Kortazar, Juan Mari Lekuona, José María Velez de Mendizabal (arg). 1983. Gabonetako Ikuskizuna (Acto para la Nochebuena). VitoriaGasteiz : Arabako Foru Aldundia.

Laka, Itziar. 1990. Negation in Syntax: On the nature of functional categories and projections. Doctoral dissertation, MIT. 
Lakarra, Joseba. 1996. Refranes y Sentencias (1596). Ikerketak eta edizioa. Bilbao : Euskaltzaindia.

Ledgeway, Adam. 2012. From Latin to Romance. Morphosyntactic Typology and Change. Oxford: Oxford University Press.

Michelena, Luis \& Ibon Sarasola. 1990. Textos arcaicos vascos-Contribucion al estudio edicion de textos antiguos vascos. Anejos del Anuario del Seminario de Filologia Vasca Julio de Urquijo, XI. Donostia : Gipuzkoako Foru Aldundia-Euskal Herriko Unibertsitatea.

Mounole, Celine. 2006. Quelques remarques à propose de l'histoire des periphrases basques. In J.A. Lakarra and J.I. Hualde (arg) Studies in Basque and Historical linguistics in Memory of R.L. Trask. Bilbo: Euskal Herriko Unibertsitatea. 723-738.

Mounole, Celine. 2007. Perifrasi zaharra mendebalde eta erdialdeko euskara zaharrean: azterketa kuantitatiboa eta proposamen berria. ASJU XLI-1. 67-138.

Mounole, Celine. 2011. Le verbe basque ancient : étude philologique et diachronique. Thèse doctorale. University of the Basque Country (UPV-EHU)/Université de BordeauxMontaigne (UBM).

Nespor, Marina \& Irene Vogel. 1986. Prosodic Phonology. Dordrecht: Foris.

Vincent, Nigel. 1982. The Development of the Auxiliaries Habere and Esse in Romance. In Nigel Vincent (arg). Studies in the Romance Verb. London: Croom Helm. 71-96.

Zaring, L. 1996. Two be or not two be" Linguistics and Philosophy 19 (2). 103-142.

Zuazo, Koldo. 1998. Euskalkiak. Euskararen dialektoak. Donostia: Elkar. 